\title{
IdeAs
}

Idées d'Amériques

\section{La revista Inimigo Rumor y las prácticas vanguardistas}

La revue Inimigo rumor et les pratiques d'avant-garde

The Journal Inimigo rumor and its Avant-Garde Practices

\section{Susana Scramim}

\section{(2penEdition}

\section{Journals}

\section{Édition électronique}

URL : https://journals.openedition.org/ideas/2071

DOI : 10.4000/ideas.2071

ISSN : 1950-5701

\section{Éditeur}

Institut des Amériques

\section{Référence électronique}

Susana Scramim, «La revista Inimigo Rumor y las prácticas vanguardistas », IdeAs [En ligne], 9| 2017, mis en ligne le 18 juillet 2017, consulté le 19 octobre 2022. URL : http://journals.openedition.org/ ideas/2071 ; DOI : https://doi.org/10.4000/ideas.2071

Ce document a été généré automatiquement le 19 octobre 2022.

\section{(i) $९$}

Creative Commons - Attribution - Pas d'Utilisation Commerciale - Pas de Modification 4.0 International - CC BY-NC-ND 4.0

https://creativecommons.org/licenses/by-nc-nd/4.0/ 


\title{
La revista Inimigo Rumor y las prácticas vanguardistas
}

\author{
La revue Inimigo rumor et les pratiques d'avant-garde \\ The Journal Inimigo rumor and its Avant-Garde Practices
}

\section{Susana Scramim}

\section{La revista}

La revista Inimigo Rumor, editada por el poeta Carlito Azevedo en la editorial 7 Letras de Río de Janeiro entre los años de 1996 y 2008, ha sido orientada por la valorización y divulgación de un modo muy singular de hacer la poesía. Mientras fue publicada la revista, tuvo fuerte presencia la práctica poética desarrollada por diferentes vanguardias artísticas de la segunda mitad del siglo XX en Brasil, Francia, Portugal y Argentina. Empezando por la influencia que recibió de la vanguardia brasileña del Concretismo y de sus conquistas formales en relación con el uso tradicional del verso en la poesía, posteriormente se desdobló en una valorización de la práctica poética del poema hecho con la materia de lo cotidiano y con un gusto marcado por lo informe, venido de la vanguardia de los poetas «marginales» de Río de Janeiro -algo que podría parecer contradictorio si se tiene en cuenta que tal modo de entender y practicar el verso se opone a la propuesta concretista.

La revista divulgaría, por un lado, la poesía de Rui Belo y Adília Lopes, poetas portugueses, así como la producción de los argentinos Tamara Kamenszain y Arturo Carrera, que en sus obras retoman el interés por lo informe y lo cotidiano, demarcando la relación establecida con los «marginales». Por otro lado, la publicación se reorientaría en dirección a la constatación y reflexión francesa sobre la retomada del prestigio del verso y de la (re)formalización de la poesía, a partir de la divulgación de ensayos y poemas de Michel Deguy, Jean-Marie Gleize y Nathalie Quintane. La práctica editorial de la revista Inimigo Rumor no fue propiamente vanguardista, con todo, tuvo en cuenta la declaración del poeta Haroldo de Campos, que afirmó en 1981 que el ciclo de las vanguardias estaba terminado y que éstas ya no podrían tener existencia 
efectiva, pues los tiempos eran post-utópicos. Sin embargo, lo que propongo en mi lectura es que la revista ha trabajado bajo la perspectiva de acción de la vanguardia sin ser propiamente una publicación vanguardista. Además de eso, propongo que ese modo muy particular de usar los poemas y ensayos de los vanguardistas fue otra manera de seguir con ellos.

Otras miradas críticas, a su vez, leyeron el trabajo del poeta Carlito Azevedo, en su función de editor de la Inimigo Rumor, como el fruto de una experiencia sutil, compleja y derivada de su competencia como poeta. A ese respecto, en « Plvs élire que lire », Maria Lúcia de Barros Camargo destaca la rigurosa relación con la tradición poética y una vivencia simultánea en esa tradición, un ir y venir entre la experiencia y la vivencia (visceral) de/con la tradición. Italo Moriconi, en «Pós-modernismo e a volta do sublime na poesia brasileira» (1998), así como en "Qualquer coisa fora do tempo e do espaço (poesia, literatura e pedagogia da barbárie)» (1999) y, finalmente, en Como e por que ler a poesia do século XX (2002), asocia los proyectos literarios -según el crítico carioca generalmente «individuales», «autoformativos»- que giran alrededor de la revista Inimigo Rumor al descuido que los sujetos que se empeñan en esos proyectos cultivan en relación con sus responsabilidades sociales o civiles. Elisa Helena Tonon, en su investigación sobre la poesía contemporánea, sus revistas y antologías, especialmente la Inimigo Rumor, analizó el carácter antológico de la revista y la función de archivista que su editor asumió desde el lanzamiento del primer número. La investigadora se propone en ese trabajo «desleer» la «revista archivo», buscando en ella lo que se presenta como falta, de acuerdo con la acción crítica diagnosticada por Walter Benjamin en sus tesis sobre el concepto de historia, es decir, peinar la historia a contrapelo. Con levantamientos precisos de los veinte números de la revista, analizados en esa investigación, Tonon constata que las presencias de los poetas Paulo Leminski ${ }^{1} \mathrm{y}$ Roberto Piva están obliteradas, tal vez porque sus poéticas se caracterizan por cierto anarquismo poético (Tonon E.H., 2008: 7). De alguna manera, eso confirma el análisis de Moriconi, que diagnosticaba: «en un grupo como el de la revista Inimigo Rumor, opera el concepto de una responsabilidad con la literatura, por ahora sublunar, adiliana (de Adília Lopes, la poeta portuguesa). En los grupos más al sur, sobrevive la contracultura $»^{2}$ (Moriconi I., 2002: 136).

En 1997, Carlito Azevedo asumió el proyecto de constitución de la revista Inimigo Rumor. Inicialmente estuvo acompañado en la dirección por Júlio Castañon Guimarães; luego, a partir del número 7, por Augusto Massi. En los números 11 al 15, el poeta Marcos Siscar, que tuvo sus primeros poemas publicados por Carlito Azevedo en las páginas de Inimigo Rumor, se integró al grupo de editores de la revista de ese momento. En los mismos números, las editoriales portuguesas Cotovia y Ângelus Novus compartieron la publicación de la revista con las editoriales brasileñas 7Letras y Cosac Naify. En 2004, en el número 16, Carlito Azevedo cambió el lugar originario de editor por el llamado «consejo editorial», del que participa un número considerable de poetas ${ }^{3}$. Sin embargo, incluso desde ese nuevo lugar, un lugar compartido de consejería editorial, o incluso, como quería João Cabral de Melo Neto, de «escogedores» de poesía, Carlito Azevedo continuó ejerciendo una función que no quería ejercer, según declaró en la entrevista otorgada al suplemento «Ideias» del Jornal do Brasil, en 1996. Decía entonces que prefería cuando el tema era la pintura: «Hasta hoy, cuando escribo crítica, no me gusta escribir sobre poesía, y sí sobre pintura, tema con el que me siento en mejor disposición para el diálogo» ${ }^{4}$. 
Y más: además de desempeñar un papel como formador en la práctica de edición de poesía, pasó a actuar en la formación de esos poetas que gravitaban en torno a la revista, no solamente con la publicación de sus poemas, sino integrando el propio consejo editorial. Había excepciones, claro está; sin embargo, de manera general, todos los poetas que actuaron en el consejo editorial son, o fueron, jóvenes que publicaron por primera vez sus poemas en la Inimigo Rumor.

\section{Revista entre revistas}

Resulta interesante observar cómo y por cuánto tiempo la actividad de los editores de revistas de poesía en el Brasil de la década de 1990 funcionó como una actividad crítica, ejercida a partir y desde dentro de la propia poesía. Maria Lúcia de Barros Camargo, en un análisis vertical de la presencia de las revistas de poesía Inimigo Rumor, Azougue y Medusa, observa que la primera «no es una revista que desee estar 'en contra' de algo. Por el contrario, desea ser simplemente poesía» (Camargo M.L. de B., 2001: 43)5. Escribe aún que, en su primero número, la Inimigo Rumor publica una carta de João Cabral de Melo Neto a Clarice Lispector, en que el poeta comenta el proyecto de creación de una revista cuyo nombre debería ser «ANTOLOGIA (dístico: PLVS ÉLIRE QUE LIRE)». Una revista, según el propio João Cabral, cuyos directores tendrían la función de escoger -y él, como director principal, ya estaba ejerciendo el papel de director-escogedor, pues proponía a Clarice que ella participase como seleccionadora-. Maria Lucia de Barros Camargo llama la atención sobre el hecho de que la Inimigo Rumor asumiría esa función pasados cincuenta años desde la proposición de Cabral. Sin embargo, advierte Camargo, si el principio selectivo es muy fuerte, «escoger lo que nos sirve a todos... $)^{6}$, según la carta de Cabral, «contrasta, no obstante, con los principios de desjerarquización y despersonalización que parecen organizar la presentación de poemas y ensayos» (Camargo M.L. de B., 2001: 44)7. El análisis de Barros Camargo, de 2001, abarca los diez números publicados de la revista, hasta la fecha del ensayo. Antes, en 1998, Italo Moriconi, en una conferencia proferida en el VI Congreso de la Asociación Brasileña de Literatura Comparada (ABRALIC), subrayaba que Inimigo Rumor, que en la época contaba apenas con cuatro números publicados, seguía su propuesta inicial, asumida "oblicuamente», dado que no se explicitaba eso en el editorial de la revista sino a través de la carta de Cabral a Clarice. "Antes elegir que leer» ${ }^{8}$, es el dístico que Cabral ideó a partir de Paul Valéry, para la revista ANTOLOGIA. Moriconi analiza el hecho de que no sean informadas las «biobibliografías» de los poetas, así como las informaciones laterales sobre los poemas publicados, lo que para el crítico carioca configura una efectuación de la propuesta de João Cabral, en el sentido de ser una revista para pocos, los doscientos lectores a que se refería el poeta pernambucano; Inimigo Rumor se dedica a lectores que conocen el ABC de la poesía. Lo que Moriconi ponía en debate con esa consideración era el tipo de pedagogía que envuelve y fundamenta la práctica del crítico, en este caso una práctica selectiva, electiva, de la revista y de su editor.

\section{¿Una pedagogía?}

¿Cómo relacionar esa pedagogía de la elección, que en un principio estaría desarrollándose en las páginas de los cuatro primeros números de la Inimigo Rumor, con 
lo que afirmábamos antes, en el libro sobre la poesía de Carlito Azevedo publicado en la colección Ciranda de Poesía", sobre la potencia de la poesía-espejo, de la poesía "a la manera de», del poema-imagen especular, en el trabajo poético de Carlito Azevedo? ¿Cómo pensar esa relación? ¿Cómo pensar el desvío del sujeto todopoderoso operado por esa poesía que desea distinguirse sin discriminar, que desea ser elegante sin elegir? Tal vez convenga, para responder esas preguntas, retornar a Paul Valéry y João Cabral de Melo Neto. Para el poeta francés, el proceso de formación de los seres humanos debería consistir en hacerles comprender que deberían detenerse más sobre las cosas y aprender de nuevo de ellas porque «una obra de arte debería siempre enseñarnos que no habíamos visto lo que vemos. La educación profunda consiste en deshacer la educación primaria» (Azevedo C., 1991: 145) ${ }^{10}$.

Así, no se trata de elegir (del latín eligere, al provenzal elegir, eligir eleger, eslire, eslir), sino de alcanzar la elegancia (elegant, [eleg]ante), sino de distanciarse de esa etimología moderna que enseñaba que elegante es aquel que sabe elegir discriminando. En los versos de João Cabral de Melo Neto, distinguiéndose de aquellos que quieren ejercer la cualidad de «escogedores», la educación por la piedra es impersonal, predidáctica, es un «aprender» y no un «enseñar». Hay cosas que el «cañaveral» aprende, así como hay cosas que el «mar» aprende,

Lo que el mar no aprende del cañaveral:

la vehemencia pasional de la pleamar;

el mortero-pilón de las olas en la arena,

molida y menuda, pilada de lo que pilar.

(Melo Neto, J.C., 2003: 335) ${ }^{11}$

La educación en los poemas de João Cabral de Melo Neto es impersonal. Por eso se trata de una elegancia sin elección, pues en la buena elección reside el sujeto que enseña lo que supo discriminar como bello:

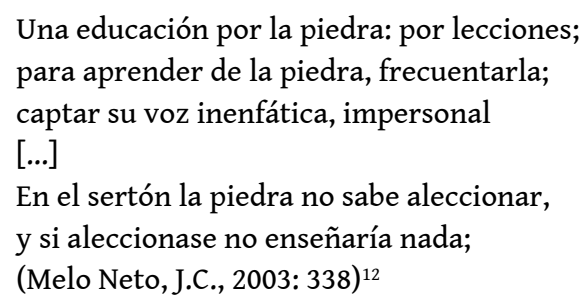

Estamos ante una pedagogía del «frecuentar» las cosas y de ese contacto tomar la «lección» que, tanto para Cabral como para Valéry, es «moral». Retomemos la noción de «bello estratégico» de Baltasar Gracián, que se desprende de su concepto de agudeza y se sitúa en el polo opuesto de la noción de lo «bello como lugar de conciliación y de desinterés del cual nació y en el cual se fundamentó la estética del siglo XVIII» (Perniola M., 2009: 173) ${ }^{13}$. Lo bello, finalidad de toda educación y de toda moral en la concepción estético-práctica de Gracián, debe usarse primordialmente para sustraerse y deshacerse de amarras, antes que para imponerse. Lo bello agudo, con su poder de penetración en el comportamiento humano, debe pensarse como el medio más sutil del conocimiento y del autoconocimiento. Educación por la piedra, frecuentar las cosas, deshacerse de la educación primaria, publicar una revista que quiere distinguirse sin discriminar, que desea la elegancia sin la elección, esa es una estética que comporta un marcado carácter práctico y, paradójicamente, vanguardista. 


\section{Lecciones}

La traducción es un medio por el cual un poeta se construye y construye su camino. En 1962, Haroldo de Campos daba cuenta de que la traducción de poesía proporciona al poeta una «vivencia interior del mundo y de la técnica de lo traducido» (de Campos $\mathrm{H}$., 1962: 31) ${ }^{14}$. Para Campos, de la misma manera, los primeros movimientos del traductor configurarían una tradición activa a la cual el poeta comenzaría a afiliarse, con ello anticipando conexiones y produciendo nuevas relaciones a partir de la misma tradición. Por ello, concluye Haroldo, la traducción de poesía es «un ejercicio de intelección y, a través de él, una operación crítica en vivo» (de Campos H., 1962: 32) ${ }^{15}$. Más de veinte años después, en «Para além do princípio da saudade», Haroldo de Campos desarrollaría en diapasón benjaminiano su tesis sobre la actividad del traductor de poesía. Allí, retomando las reflexiones de Walter Benjamin sobre la tarea/ renuncia del traductor, se ratifica la tesis del filósofo alemán que reza que la traducción no revela, sino que demuestra, «como un modelo intensivo y anticipatorio, la relación oculta entre las lenguas» (Benjamin W., 2001: 9) ${ }^{16}$. En ese sentido, en este texto en que intento presentar el trabajo editorial de la revista Inimigo Rumor y de su editor, el poeta Carlito Azevedo, arriesgo una aproximación entre el trabajo del coleccionista y el del traductor. La tarea del coleccionista, para Benjamin, es reunir anárquicamente los objetos para destruir la ligazón con el contexto del que formaban parte, con la finalidad de hacer aparecer las semejanzas entre las cosas y, así, crear otras relaciones de similitud; esa actitud lo aproxima al mundo del artista, cuya lidia con las formas reenciende el lenguaje mudo de las cosas. El traductor, para el filósofo alemán, tiene como tarea hacer aparecer la afinidad sorda entre las lenguas en base a la percepción de la afinidad muda entre las cosas, afinidad que toma cuerpo en la actividad del coleccionista. Ambos trabajos, el de la traducción y el de la colección, toman la sobrevivencia o la vida póstuma de las cosas como la característica más importante de sus oficios, cuando tratan de ver y volver a producir relaciones de sobrevida con los objetos que reúnen, seleccionan y guardan ${ }^{17}$.

Carlito Azevedo tradujo, en 1992, libros de Benjamin Constant y Alfred Jarry; en 1995, de André Chouraqui; en 2001, Bibliomania, de Gustave Flaubert; en 2003, «En una noche oscura», de Juan de la Cruz, para la edición del ensayo crítico de Leo Spitzer, «Sobre tres poemas del éxtasis», cuya traducción había sido publicada inicialmente en las páginas de Inimigo Rumor (n. 12) en 2002. Los traductores de los otros dos poemas que componen la edición son Augusto de Campos, traductor de «El éxtasis» de John Donne, y Haroldo de Campos, que tradujo el «Canto de amor» de Tristán e Isolda de Richard Wagner. Además de eso, Carlito tradujo a varios otros poetas cuyos trabajos fueron publicados en Inimigo Rumor, como Gonzalo Rojas, Alberto Girri, Liliana Ponce, Andi Nachon, Reynaldo Jiménez, José Emílio Pacheco, C. Tarkos, Philippe Beck, entre otros.

En la labor del traductor, que para Azevedo se hace también a través de la poesía, se despliega la actividad crítica del poeta. Si la traducción es una de las prácticas que ofrecen al poeta el conocimiento de su oficio y su propio autoconocimiento, mediante el conocimiento de la lengua, esa práctica no se separa -e incluso, corre paralela- de la función del coleccionista-crítico. Como coleccionista-crítico, Carlito Azevedo editó y, en algunos casos, lanzó al mercado editorial brasileño -ya sea como editor de la Inimigo Rumor ya sea como coordinador de la colección de libros de poesía Ás de colete de la editorial 7Letras- a varios poetas que componen hoy la escena poética en Brasil. Entre 
esos poetas están: Marcos Siscar, Paula Glenadel, Marília Garcia, Aníbal Cristobo, Tarso de Melo, Angélica Freitas y Ricardo Domeneck. En el año 2000, reeditó el libro de poemas Beijo na boca, de Cacaso, y en esa edición escribió su lección de crítico: «Beijo na boca fue llamado la educación sentimental de la generación del $68 »^{18}$. En la colección Ás de colete, también editó a poetas que habían construido un transcurso textual de aliento, demostrando los lugares por los que circulaban sus intereses en la poesía brasileña contemporánea de la colección -a partir de 2002: Adília Lopes, Antonio Cisneros, Michel Deguy, Francisco Alvim, el mismo Cacaso, Orides Fontela, Age de Carvalho, Nathalie Quintane, Fabiano Calixto y Júlio Castañon Guimarães. De esa manera, Azevedo configura la tarea iniciada de crear una colección, organizar un camino, al tiempo que propone una manera de aprender y aprehender la poesía. Cuando la Inimigo Rumor tuvo diez años, Carlito Azevedo, en una entrevista conmemorativa del vigésimo número publicado, ofreció un esbozo del resultado de su opción por la traducción como tarea complementaria a la colección:

Aprendí con el tiempo que se debe dar el mayor énfasis a la traducción de poesía, de los ensayos y también de los poetas más jóvenes, y eso por una razón práctica. Ese es el material que se enfrenta con mayores dificultades para su publicación en libro. Con todos los inconvenientes del sistema editorial, los poetas brasileños conocidos dejan sus producciones en buenas editoriales, como la Ateliê Editorial, la 34, la Iluminuras, para no hablar de las editoriales pequeñas, que ya son legión. Pero es bien difícil que los ensayos o las traducciones que publicamos salgan en libro. Un ejemplo: las traducciones de Stefan George y Gottfried Benn, que Haroldo de Campos publicó con nosotros en 1997, siguen inéditas hasta hoy. Lo mismo ocurre con las traducciones de Frank O'Hara, realizadas por Paulo Henriques Britto y Luiza Franco Moreira, publicadas en la revista. Y para los poetas nuevos la publicación es todavía más difícil. A veces ellos aún ni siquiera tienen un libro listo, como en el caso de la joven Juliana Krapp, una campeona de peticiones de libros en la editorial. Muchos lectores buscan la 7Letras para comprar el libro de Juliana, porque se entusiasmaron con los poemas que leyeron, y ella ni siquiera ha lanzado un libro. (Azevedo C., 2008: 1) ${ }^{19}$

En 1998, Carlito escribió sobre el libro de poemas de Haroldo de Campos, Crisantempo, y, como un coleccionista, analizó:

En Crisantempo [...] Haroldo de Campos prefiere el movimiento oscilatorio entre la economía de medios y la afluencia, entre el ornamento y la depuración, entre la celebración y la denuncia, entre las «sutilezas» y las "groserías», de un modo tan desconcertante que, si al final de cuentas aún podemos afirmar que se trata de un bello libro, es porque, citando a Barthes de nuevo, aprendemos a comprender la belleza ya no como algún tipo de conformidad «a un ideal canónico», sino como una «plenitud material de placeres». (Azevedo C., 1998: 1)20

El valor de los poemas que componen el libro de Haroldo de Campos reside, para el poeta-crítico, en su facultad de crear la «belleza estratégica», que no tiene ninguna relación con el poder discriminatorio del canon, sino que desea la distinción como plenitud material de placeres. Lo «bello estratégico» está relacionado con una economía de los afectos aplicada al conocimiento de las cosas.

En 2002, Carlito escribió un ensayo sobre João Cabral de Melo Neto, que salió publicado en la antología del poeta pernambucano, organizada por Luiz Raul Machado. Allí el poeta destaca, como ya lo había hecho en su análisis de Crisantempo, de Haroldo de Campos, el aspecto de la belleza estratégica como valor a observarse en el poema. Propone que el rigor de los poemas de João Cabral no conduce a una poesía «árida, seca, incapaz de provocar el entusiasmo y la emoción» (Azevedo C., 2002a: 106) ${ }^{21}$. Por el 
contrario, el rigor y la construcción exacta procuran afilar el lenguaje, como se puede verificar en poemas del libro A escola das facas, de Cabral:

Además de esas influencias anotadas, la poesía española tradicional [fue fundamental] en el proceso de construcción de la voz poética de João Cabral [...]. Lo que Cabral pretendía era un entusiasmo con fibra, no alienado, una emoción que no diera descanso al intelecto, sólo así resguardaría al lector de las emociones baratas con las que artistas menos escrupulosos (sean poetas, actores de telenovelas, directores de cine, etc.) intentan seducir al público. (Azevedo C., 2002a: 105-106) ${ }^{22}$

Los procedimientos que la poesía de Carlito Azevedo rememora y colecciona se enfrentan a la necesidad más urgente y exigente de enunciarse en el tiempo presente y que, de manera ambivalente, la incapacitan para ser fiel a esas rememoraciones. Esos procedimientos se transforman en experiencia poética porque son reenunciados con la agudeza del presente y adquieren así la función de penetrar, provocar y duplicar. Simultáneamente, con el más alto índice de observación del comportamiento retórico del lenguaje, la experiencia poética se produce en el acto de conocer las pasiones propias en las pasiones del otro.

Cuando Waly Salomão murió, en 2003, Carlito Azevedo publicó, en la última página de la Inimigo Rumor (n. 14), un texto sobre el poeta bahiano. Ese texto tenía la función de homenaje, en que se enunciaba una declaración de amistad poética, y se anunciaba una futura reconciliación pública de los dos poetas, pues existían discrepancias entre ellos:

Recientemente, en el (re)lanzamiento del libro $O$ jogo do Ifá, de la amiga en común Sônia Coutinho, esbozamos un principio de reconciliación. [...] Acordamos un encuentro en el que me mostraría algunos poemas nuevos para la revista. Había algo de infantil en decirme que no comentara con nadie nuestra reconciliación («sólo se lo voy a decir a Antônio Cícero»), quería que todos se sorprendieran al ver sus poemas en Inimigo Rumor. Ese encuentro acabó no ocurriendo nunca. (Azevedo C., 2003: 242$)^{23}$

Carlito decía que veía al Waly Salomão de la década de 1980 «muy cercano a la cultura oficialista»:

Intentó adaptarse al nuevo momento y a partir de entonces fue corriente sorprender al poeta muy ansioso por la institucionalización de su nombre, por los premios y por el reconocimiento oficial. A veces daba la impresión de avergonzarse por haber escrito letras de canciones, decía querer discutir la «alta cultura». En el cortísimo periodo en que fuimos amigos, si le preguntaba sobre alguna canción que me interesaba, acostumbraba interrumpirme diciendo: «Carlito, léame sus traducciones de Pierre Reverdy, eso es lo que interesa». Después se reconcilió con la MPB, «gracias al grupo Rappa», decía, que había grabado una estupenda versión de la canción «Vapor barato» (Jards Macalé e Waly Salomão). (Azevedo C., 2003: 242)24

Sin embargo, reconoce en el mismo texto que tal vez su estilo provocativo, agitador, excesivo, le había hecho necesariamente librarse de la «cultura oficialista»:

Tal vez sea una prueba de su grandeza el hecho de que esas tentativas de aproximación de la oficialidad académica nunca funcionaron muy bien. Su personalidad transgresiva siempre sobresalía, y no era sin alguna molestia que lo recibían los sectores oficiales a los que se acercaba. Esa inadaptación, lejos de ser un defecto, revelaba, eso sí, una gran cualidad. De los libros que publicó en ese periodo, sólo me gustó integralmente Armarinho de miudezas, mezcla de géneros que parecía indicar un retomar del impulso inicial. (Azevedo C., 2003: 242) ${ }^{25}$

Waly Salomão, que en 2001 había interpretado a Gregório de Mattos en el cine, en el film homónimo de Ana Carolina, citaba en sus textos al jesuita Baltasar Gracián. En «Contradiscurso», publicado en 1980, como parte del libro Armarinho de miudezas, 
Salomão cita a Gracián en el epígrafe del texto: " [...] y vive al siglo de oro interiormente» (El discreto).

De cierta manera, Carlito Azevedo y Waly Salomão ya se habían reencontrado antes de la tentativa de reconciliación mencionada hace poco, es decir, el punto de reencuentro tal vez haya sido el cruce de algunos de los poemas de los dos. Con el poema «Novelha cozinha poética» ${ }^{26}$ del libro Tarifa de embarque (2000), y el ensayo "Contradiscurso» (1980), de Salomão, y con el poema «A situação atual da poesia no Brasil», de Collapsus linguae (1991), de Azevedo, los dos poetas desarrollan un sentido moral que atraviesa los «lugares comunes», aunque eso no quiere decir que esos lugares se limiten apenas a figuras, a los topoi que visitan simultáneamente. Esas figuras se toman en su aspecto de materia poética y son figuras retóricas de la misma poesía, que se mezclan en el plano existencial del problema vivido en la querella entre los dos poetas ${ }^{27}$. El texto «Contradiscurso»-que se contraponía en ese momento a los análisis de Carlos Alberto Messeder Pereira, autor de Retrato de Época: poesia marginal - anos 70 (1981)- reforzaba su posición contraria al abordaje sociológico de la poesía, un abordaje modernista, cuyo único resultado era cambiar el concepto de «movimiento literario» por el de «época». En el poema de Carlito Azevedo, «A situação atual da poesia no Brasil», la posición consistía en contraponerse a la dinámica de la poesía brasileña, siempre indecisa entre la «cosa mentale» y la «cosa nostra», entre la propuesta de nuevos proyectos y antiguas y actuales «camarillas» ${ }^{28}$. Los lugares comunes a los que se refieren los poemas y el ensayo no son los mismos. Sin embargo, el «modo», la «manera» de escribir, los pone en sintonía en un mismo pensamiento sobre lo bello, la estética y la poesía.

La revista Inimigo Rumor, en sus veinte números publicados a lo largo de diez años, del 1996 a 2008, produjo un debate fuera de los límites normativos de una vanguardia, aunque guardando de la vanguardia la potencia de producir una reflexión calificada y consciente de su función, entre la normatividad y las oposiciones a ella en la práctica poética brasileña contemporánea. Su política editorial supo que no podría abdicar del proceso de creación como escritura, cada vez que es en ella, en la escritura, que se da la formulación de un «sujeto moderno», y mucho menos podría abdicar de la condición de diálogo con otras formas de arte y de discurso, pues entraría en duelo mortal con eso mismo que la constituye: la crisis de su propia autonomía. Además de eso, estuvo consciente de que el proceso de creación estética tiene la potencia de crear mundos y, por lo tanto, tampoco puede renunciar a cierto concepto de arte como forma. No obstante, sin pretender que el producto final se estabilizase en una forma fija, apostó por la concepción de una poesía que tuviera a lo «informe» en el horizonte de sus búsquedas, un «informe» que, según la propuesta del Georges Bataille de 1929, no sería solamente un adjetivo con un determinado sentido, sino también un «término que sirve para descalificar, exigiendo generalmente que cada cosa tenga su forma. Lo que esa palabra designa carece de derecho propio en cualquier sentido y se propaga por todas partes, como una araña o un gusano» (Bataille G., 2003: 55) ${ }^{29}$. 


\section{BIBLIOGRAPHIE}

Agamben, Giorgio, Infância e história, Tradução de H. Burigo, Belo Horizonte, EDUFMG, 2005.

Andrade, Carlos Drummond de, Poesia completa, Río de Janeiro, Nova Aguilar, 2002.

Azevedo, Carlito, Collapsus linguae, 2 ed. Río de Janeiro, 7Letras, 1998 [1991].

Azevedo, Carlito, As banhistas, Río de Janeiro, Imago, 1993.

Azevedo, Carlito, Entrevista, Jornal do Brasil, 14 dez. 1996, Ideias \& Livros.

Azevedo, Carlito, Sob a noite física, 3 ed. Río de Janeiro, 7Letras, 1997 [1996].

Azevedo, Carlito, «O espaço curvo da poesia», Folha de São Paulo, 27 set. 1998.

Azevedo, Carlito, Sublunar, Río de Janeiro, 7Letras, 2001a.

Azevedo, Carlito, Versos de circunstancia, Río de Janeiro, Moby Dick, 2001b.

Azevedo, Carlito, «Para continuar a conversa», In Machado, Luiz Raul, Novas Seletas. João Cabral de Melo Neto, Río de Janeiro, Nova Fronteira, 2002a.

Azevedo, Carlito (ed.), O Quarto-Zagueiro (documento de Word), 2002b.

Azevedo, Carlito, «Waly Salomão», Inimigo Rumor, Río de Janeiro, 2003, n. 14.

Bataille, Georges, «La voluntad de lo imposible», La felicidad, el erotismo y la literatura. Ensayos 1944-1961, Selección, traducción y prólogo de Silvio Mattoni, Buenos Aires, Adriana Hidalgo, 2004.

Bataille, Georges, Informe, La conjuración sagrada. Ensayos 1929-1939, Selección, traducción y prólogo de Silvio Mattoni. Buenos Aires, Adriana Hidalgo, 2003.

Baudelaire, Charles, As flores do mal, Tradução de Ivan Junqueira, Río de Janeiro, Nova Fronteira, 1985.

Benjamin, Walter, «Eduards Fuchs, der Sammler und der Historiker», Gesammelte Schriften, II. 2, Frankfurt, Suhrkamp, 1977.

Benjamin, Walter, Charles Baudelaire. Um lírico no auge do capitalismo, São Paulo, Brasiliense, 1994.

Benjamin, Walter, Rua de mão única, São Paulo, Brasiliense, 1994.

Benjamin, Walter, «A tarefa do tradutor», Tradução de Susana Kampff Lages, in Heidermann, Werner (org.), Clássicos da teoria da tradução, Florianópolis, EDUFSC, 2001.

Camargo, Maria Lúcia de Barros e Célia Pedrosa (orgs.), Poesia e contemporaneidade: leituras do presente, Chapecó, Argos, 2001.

Campos, Haroldo de, «Da tradução como criação e como crítica», Metalinguagem. São Paulo, Cultrix, 1962.

Campos, Haroldo de, «Para além do princípio da saudade», Folha de São Paulo, 09 dez. 1984, Folhetim.

Campos, Haroldo de, A educação dos cinco sentidos, São Paulo, Brasiliense, 1985.

Campos, Haroldo de, O arco-íris branco, Río de Janeiro, Imago, 1997.

Campos, Haroldo de, El discreto, Madrid, Alianza Editorial, 1997.

Gracián, Baltasar, Oráculo manual, Madrid, Castalia, 2003. 
Ivo, Ledo, O preto no branco, Río de Janeiro, Livraria São José, 1955.

Jesi, Furio, Lettura del «Bateau ivre» di Rimbaud, Macerata, Quodlibet, 1996.

Mallarmé, Stéphane, CEuvres complètes I, Paris, Gallimard, 1998.

Mallarmé, Stéphane, «Crise de verso», Tradução de Ana Alencar, Inimigo Rumor, Río de Janeiro, $2008, n^{\circ} 20$.

Melo Neto, João Cabral de, Obra completa, Río de Janeiro, Nova Aguilar, 2003.

Mendes, Murilo, Poesia completa e prosa, Río de Janeiro, Nova Aguilar, 1994.

Molder, Maria Filomena, Semear na neve, Estudos sobre Walter Benjamin, Lisboa,

Relógio d'água, 1999.

Moriconi, Italo, «Pós-modernismo e a volta do sublime na poesia brasileira», in Pedrosa, Célia et al. (orgs.), Poesia hoje, Niterói, EDUFF, 1998.

Moriconi, Italo, «Qualquer coisa fora do tempo e do espaço (poesia, literatura e pedagogia da barbárie) », in Andrade, Ana Luiza et al. Leituras do ciclo, Ilha de Santa Catarina, ABRALIC, Chapecó, Grifos, 1999.

Moriconi, Italo, Como e por que ler a poesia brasileira do século XX, Río de Janeiro, Objetiva, 2002.

Pedrosa, Célia, «Traços da memória na poesia brasileira contemporânea». Mais poesia hoje, Río de Janeiro, 7Letras, 2000.

Pedrosa, Célia e Camargo, Maria Lúcia de Barros (orgs.), Poéticas do olhar e outras leituras de poesía, Río de Janeiro, 7Letras, 2006.

Pereira, Carlos Alberto Messeder, Retrato de época: poesia marginal - anos 70, Río de Janeiro, Funarte, 1981.

Perniola, Mario, Enigmas. Egípcio, barroco e neobarroco na sociedade e na arte, tradução Carolina Pizzolo Torquato, Chapecó, Argos. 2009.

Prigol, Valdir, «Mire: veja - a solicitação do olhar nos poemas de Carlito Azevedo», in Pedrosa, Célia e Camargo, Maria Lúcia de Barros (orgs.), Poéticas do olhar e outras leituras de poesía, Río de Janeiro, 7 Letras, 2006.

Resende, Beatriz, «O que me interessa é o político no literário» (entrevista a Miguel Conde), 0 Globo, 30 ago. 2008, Prosa \& Verso.

Revista Anhembi, São Paulo, fev. 1951, v. I, n. 3, mai 1951, v. II, n. 6.

Revista Inimigo Rumor, n. 20, primeiro semestre de 2008.

Sally, Daniele Santana, «Poesia e visualidade em Carlito Azevedo», in Camargo, Maria Lúcia de Barros e Pedrosa, Célia (orgs.), Poesia e contemporaneidade: leituras do presente, Chapecó, Argos, 2001.

Salomão, Waly, Tarifa de embarque, Río de Janeiro, Rocco, 2000.

Salomão, Waly, Armarinho de miudezas, Río de Janeiro, Rocco, 2005.

Santiago, Silviano, «As ilusões perdidas da poesia», Jornal do Brasil, 15 dez. 2001.

Scramin, Susana, Literatura do presente: história e anacronismo dos textos, Chapecó, Argos, 2007. 
Süssekind, Flora, «A poesia andando», A voz e a série, Río de Janeiro, 7Letras; Belo Horizonte, Ed. da UFMG, 1998.

Süssekind, Flora, «A imagem em estações - observações sobre 'Margens', de Carlito Azevedo», in Pedrosa, Célia e Alvez, Ida (orgs.), Subjetividades em devir: estudos de poesia moderna e contemporânea, Río de Janeiro, 7Letras, 2008.

Tonon, Elisa Helena, «O arquivo Inimigo Rumor. Escolhas e afinidades», NELIC - Boletim de Pesquisa, 2008, v. 8, n.12/13.

\section{NOTES}

1. Con excepción del ensayo de Flora Süssekind (Inimigo Rumor, n. 20), que versa sobre las "hagiografías" de vida de algunos poetas brasileños, entre las cuales incluye la venerable vida de Leminski, no hay otras referencias a ese poeta en la revista aquí abordada.

2. Todas las citaciones del portugués, en adelante, serán directamente traducidas en el cuerpo textual, reproduciéndose la citación original en el pie de página. Para el caso de esta citación: "num grupo como o da revista Inimigo Rumor, há o conceito de uma responsabilidade para com a literatura, agora sublunar, adiliana (de Adília Lopes, a poeta portuguesa). Nos grupos ao sul, sobrevive a contracultura". (N. del T.)

3. Hasta el vigésimo número de la revista Inimigo Rumor, participaron en el consejo editorial los siguientes poetas: Marília Garcia, Marcos Siscar, Augusto Massi, Jorge Viveiros de Castro, Paula Glenadel, Aníbal Cristobo, Heitor Ferraz, Valeska Aguirre, Isadora Travassos, Débora Fleck, Leonardo Martinelli, Masé Lemos, Júlio Castañon Guimarães, André Nazário, Manoel Ricardo de Lima y Franklin Alves Dassie.

4. "Até hoje, quando escrevo crítica, não gosto de escrever sobre poesia, e sim sobre pintura, assunto com o qual me sinto mais à vontade para dialogar".

5. "Não é uma revista que deseja ser 'contra' algo. Ao contrário, deseja ser simplesmente poesia".

6. "Escolher o que presta de todos nós...".

7. “Contrasta, porém, com os princípios de desierarquização e de despersonalização que parecem organizar a apresentação dos poemas e ensaios".

8. "Antes eleger do que ler".

9. Cf. Susana Scramim, Carlito Azevedo, Río de Janeiro, Ciranda de Poesia, Editora da UERJ, 2010.

10. "Uma obra de arte deveria sempre nos ensinar que não tínhamos visto o que vemos. A educação profunda consiste em desfazer a educação primeira".

11. "O que o mar não aprende do canavial:

a veemência passional da preamar;

a mão-de-pilão das ondas na areia,

moída e miúda, pilada do que pilar".

12. "Uma educação pela pedra: por lições;

para aprender da pedra, frequentá-la;

captar sua voz inenfática, impessoal

[...]

No Sertão a pedra não sabe lecionar,

e se lecionasse não ensinaria nada;".

13. "Belo como lugar da conciliação e do desinteresse sobre o qual nasceu e se fundamentou a estética do século XVIII".

14. "Vivência interior do mundo e da técnica do traduzido". El ensayo "Da tradução como criação e como crítica" fue presentado en el III Congreso Brasileño de Crítica e Historia Literaria, 
ocurrido en la Universidad de Paraíba en 1962. Se publicó originalmente en la revista Tempo Brasileiro (n. 4-5), entre junio y septiembre de 1963.

15. "Um exercício de intelecção e, através dele, uma operação de crítica ao vivo".

16. "Qual um modelo intensivo e antecipatório, a relação oculta entre as línguas".

17. Los dos ensayos de Walter Benjamin a que me refiero, al respecto de la analogía construida entre el traductor y el coleccionista, son: "La tarea/renuncia del traductor", publicado por primera vez en Charles Baudelaire, tableaux parisiens (posteriormente, en 1923, Benjamin lo tradujo al alemán y lo publicó en la editorial Richard Weissbach [uso la traducción de Susana Kampff Lages, publicada em Clássicos da teoria da tradução, 2001]); y, "Eduards Fuchs, der Sammler und der Historiker", incluido en las Gesammelte Schriften, II. 2, aunque originalmente escrito para la revista Sozialforschung (n. 6), publicada en 1937.

18. "Beijo na boca já foi chamado de a educação sentimental da geração de 68 ".

19. “Aprendi com o tempo que deve ser dada maior ênfase à tradução de poesia, aos ensaios e aos poetas mais novos também, e isso por uma razão prática. É o material que tem mais dificuldade de encontrar possibilidade de publicação em livro. Com toda a dificuldade do sistema editorial, os poetas brasileiros já conhecidos vêm escoando suas produções em boas editoras, como a Ateliê Editorial, a 34, a Iluminuras, sem falar nas pequenas editoras, que são legião. Mas é bem difícil que os ensaios ou as traduções que publicamos saiam em livro. Um exemplo: as traduções de Stefan George e Gottfried Benn que Haroldo de Campos publicou com a gente em 1997 estão inéditas até hoje. As traduções de Frank O'Hara feitas por Paulo Henriques Britto e a Luiza Franco Moreira, publicadas na revista, também. E para os novos poetas a publicação ainda é mais difícil. Às vezes eles ainda nem têm livro pronto, como é o caso da novíssima Juliana Krapp, uma campeã de pedidos de livro na editora. Muitos leitores procuram a 7Letras para comprar o livro dela porque se entusiasmaram com os poemas que leram, e ela nem tem livro".

20. "Em Crisantempo, ao contrário, Haroldo de Campos prefere o movimento oscilatório entre a economia de meios e a caudalosidade, entre ornato e depuração, entre celebração e denúncia, entre 'finezas' e 'grossuras', e de um modo tão desconcertante que, se no fim das contas ainda pudermos afirmar que se trata de um belo livro, é porque, citando Barthes outra vez, aprendemos a compreender a beleza não mais como algum tipo de conformidade 'a um ideal canônico', mas sim como "plenitude material de prazeres"'.

21. "Árida, seca, incapaz de provocar o entusiasmo e a emoção".

22. "Além dessas influências já anotadas, [foi fundamental] no processo de construção da voz poética de João Cabral a poesia espanhola tradicional [...]. O que Cabral pretendia era um entusiasmo com fibra, não alienado, uma emoção que não desse férias ao intelecto, só assim pouparia o leitor das emoções baratas com que artistas menos escrupulosos (sejam eles poetas, atores de telenovelas, diretores de cinema etc.) tentam seduzir o público".

23. "Recentemente, no (re)lançamento do livro 0 jogo do Ifá, da amiga comum Sônia Coutinho, esboçamos um princípio de reconciliação. [...] Combinamos um encontro no qual me mostraria alguns poemas novos para a revista. Havia algo de infantil ao me dizer que não comentara com ninguém a nossa reconciliação ('só vou falar para Antônio Cícero'), queria que todos se surpreendessem ao ver seus poemas em Inimigo Rumor. Tal encontro acabou nunca acontecendo". 24. "Tentou adaptar-se ao novo momento e a partir de então foi comum flagrar o poeta muito ansioso pela institucionalização de seu nome, por prêmios e reconhecimento oficial. Às vezes dava a impressão de envergonhar-se de ter escrito letras de música, dizia querer discutir 'alta cultura'. No curtíssimo período em que ficamos amigos, se lhe perguntava sobre alguma canção que me interessava, costumava interromper-me dizendo: 'Carlito, leia-me suas traduções de Pierre Reverdy, isso é o que interessa'. Depois, reconciliou-se com a MPB, 'graças ao grupo Rappa', dizia, que gravara uma estupenda versão da música 'Vapor barato' (Jards Macalé e Waly Salomão)". 
25. "Talvez seja uma prova de sua grandeza o fato de que essas tentativas de se aproximar da oficialidade acadêmica nunca tenham dado muito certo. Sua personalidade transgressora sempre sobressaía, e não era sem certo incômodo que os setores oficiais dos quais se aproximava o recebiam. Tal inadaptação, longe de ser um defeito, revelava, isso sim, uma grande qualidade. Dos livros que publicou no período, só gostei integralmente de Armarinho de miudezas, mistura de gêneros que parecia apontar para uma retomada do impulso inicial".

26. "Pegue uma fatia de Theodor Adorno/ Adicione uma posta de Paul Celan/ Limpe antes os laivos de forno crematório/ Até torná-la magra-enigmática/ Cozinhe em banho-maria/ Fogo bem baixo/ E depois leve ao Departamento de Letras/ Para o douto Professor dourar" (Salomão, 2000, p. 21). "Agarre una rebanada de Theodor Adorno/ Añada un filete de Paul Celan/ Limpie antes los restos de horno crematório/ Hasta tornarla magra-enigmática/ Cocine en baño de maría/ Fuego bien bajo/ Y después lleve al Departamento de Letras/ Para que el docto Profesor la dore".

27. En su libro sobre "Le bateau ivre", Furio Jesi (1996) demuestra como la obra de arte puede ser, al mismo tiempo, un lugar privilegiado y malhadado. Para ejemplificar esa oscilación, Jesi cita las palabras con que Mallarmé designa a la poesía: “calme bloc ici-bas...”. Con ese ejemplo, Jesi propone la tesis de que existe una oscilación semántica en las figuras retóricas, concretamente en el caso de su estudio sobre Rimbaud, en la expresión "lugar común".

28. A Panelinha [camarilla] era el club gastronómico creado en 1901 alrededor del que gravitaban los escritores pertenecientes a la Academia Brasileira de Letras (ABL). Machado de Assis y Olavo Bilac, entre otros escritores, fueron miembros de ese club.

29. "Termo que serve para desqualificar, exigindo geralmente que cada coisa tenha sua forma. 0 que designa carece de direito próprio em qualquer sentido e se deixa alastrar em todas as partes como uma aranha ou um verme".

\section{RÉSUMÉS}

La revue Inimigo Rumor, éditée par le poète Carlito Azevedo, dans la maison d'édition 7 Letras, de Rio de Janeiro, entre les années 1996 et 2008, s'est vue orientée par la valorisation et la diffusion d'une manière de faire de la poésie. Durant toutes ces années, on y retrouva la pratique poétique développée par différentes avant-gardes artistiques de la seconde moitié du XXème siècle au Brésil, en France, au Portugal et en Argentine. A commencer par l'influence de l'avant-garde brésilienne du Concretismo et ses conquêtes formelles par rapport à l'usage traditionnel du vers dans la poésie, puis elle se dédoubla en intégrant une valorisation de la pratique du poème fait de la matière du quotidien, avec un goût marqué pour l'informe, venu de l'avant-garde des poètes « marginaux » de Río de Janeiro ; ce qui pourrait paraître contradictoire si l'on pense qu'une telle compréhension et une telle pratique du vers s'opposent à ce que les « concretistas » proposaient à partir de leur propre avant-garde.

La revue diffuserait également, d'une part, la poésie de Rui Belo et Adília Lopes, poètes portugais, ainsi que les Argentins Tamara Kamenszain et Arturo Carrera, qui, dans leurs œuvres récupèrent cet intérêt pour l'informe et la poésie du quotidien, se démarquant des liens établis avec les "marginaux". D'autre part, elle se ré-orienterait dans le sens du constat français du vers et de la formalisation de la poésie, à partir de la diffusion des essais et des poèmes de Michel Deguy, JeanMarie Gleize et Nathalie Quintane. La pratique éditoriale de la revue Inimigo Rumor n'a pas été à proprement parlé d'avant-garde, s'en tenant à la déclaration du poète Haroldo de Campos qui affirma, en 1981, que le cycle des avant-gardes était terminé et qu'elles ne pourraient plus avoir 
de réelle existence, les temps étant devenus post-utopiques. Cependant, ce que je propose dans mon étude c'est que la revue a travaillé dans la perspective d'action de l'avant-garde, sans en faire partie véritablement, et cette façon d'utiliser les poèmes et les essais des avant-gardistes a été une manière de continuer le chemin à leur côté.

La revista Inimigo Rumor, editada por el poeta Carlito Azevedo, en la editorial 7 Letras, de Río de Janeiro, entre los años de 1996 y 2008, ha sido orientada por la valorización y divulgación de un modo de hacer la poesía en el cual, mientras fue publicada, estuvo presente la práctica poética desarrollada por diferentes vanguardias artísticas de la segunda mitad del siglo XX en Brasil, Francia, Portugal y Argentina. Empezando por la influencia que recibió de la vanguardia brasilera del Concretismo y sus conquistas formales en relación con el uso tradicional del verso en la poesía, posteriormente se desdobló en una valorización de la práctica poética del poema hecho con la materia de lo cotidiano y con gusto marcado por lo informe, venido de la vanguardia de los poetas "marginales" de Río de Janeiro; algo que podría parecer contradictorio si se tiene en cuenta que tal modo de entender y practicar el verso se opone a lo que los "concretistas" proponían con su vanguardia.

La revista igualmente divulgaría, por un lado, la poesía de Rui Belo y Adília Lopes, poetas portugueses, y los argentinos, Tamara Kamenszain y Arturo Carrera, que en sus obras retoman el interés por lo informe y la poesía de lo cotidiano, demarcando la relación establecida con los "marginales", y, por otro lado, se reorientaría en dirección a la constatación francesa del verso y de la formalización de la poesía, a partir de la divulgación de ensayos y poemas de Michel Deguy, Jean-Marie Gleize y Nathalie Quintane. La práctica editorial de la revista Inimigo Rumor no fue propiamente vanguardista, pues observó la declaración del poeta vanguardista Haroldo de Campos que afirmó, en 1981, que el ciclo de las vanguardias estaba terminado y que ya no podrían tener existencia efectiva, ya que los tiempos eran post-utópicos. Sin embargo, lo que propongo en mi lectura es que la revista ha trabajado bajo la perspectiva de acción de la vanguardia, sin serla propiamente, y ese modo de usar los poemas y ensayos de los vanguardistas fue una manera de seguir con ellos.

The journal Inimigo Rumor, edited by poet Carlito Azevedo, in the 7 Letras publishing house of Rio de Janeiro, between 1996 and 2008, was motivated by the valorization and dissemination of a specific way of doing poetry. It has published poems based on the poetic practice developed by different artistic avant-gardes in the second half of the twentieth century in Brazil, France, Portugal and Argentina. It began with the influence Azevedo received from the Brazilian avantgarde of concretism and its formal conquests in relation to the traditional use of verse in poetry. Later the journal foregrounded the practice of a poem of the quotidian, made of the matter of daily life. There was a tendency marked by the "formless" coming from the vanguard of the "marginal" poets of Rio de Janeiro. The journal would also divulge the poetry of Rui Belo and Adília Lopes, Portuguese poets, and the Argentineans, such as Tamara Kamenszain and Arturo Carrera, who in their works reappropriate the interest in the "formless" and the poetry of the quotidian, demarcating themselves from the "marginal". It also turned towards the French assertion of the poetic line and the formalization of poetry, starting with the publication of essays and poems by Michel Deguy, Jean-Marie Gleize and Nathalie Quintane. The editorial practice of Inimigo Rumor was not exactly avant-garde, since it conformed with the declaration of avant-garde poet Haroldo de Campos, who affirmed in 1981 that the cycle of the avant-garde was over and that it could no longer have an effective existence, in these post-Utopian times. However, what I propose in my reading is that the journal has worked in the perspective of an action of the avant-garde, without falling in line with it, but its way of using the poems and essays of the avant-garde remains a way to pursue the same goals. 


\section{INDEX}

Mots-clés : Revue Inimigo rumor, poésie brésilienne, avant-gardes, seconde moitié du XX, Carlito Azevedo

Palabras claves : Revista Inimigo rumor, poesía brasileña, vanguardias, segunda mitad del XX, Carlito Azevedo

Keywords : Journal Inimigo rumor, Brazilian poetry, avant-garde, second half of the XX, Carlito Azevedo

\section{AUTEUR}

\section{SUSANA SCRAMIM}

Susana Scramim (1965), professeure de théorie littéraire à l'Universidade Federal de Santa Catarina, chercheuse du Consejo Nacional de Desarrollo Tecnológico y Científico de Brasil, est docteure en théorie littéraire et en littérature comparée de l'Universidade de São Paulo (2000). Professeure invitée à la Leiden Universiteit (Holland, en 2007), elle est l'auteure du livre d'essais de critique littéraire Literatura do Presente (Ed. Argos, 2007); du livre Carlito Azevedo, pour la collection Ciranda de Poesia de l'Editorial de la Universidade Estadual do Rio de Janeiro - UERJ (2010). Parmi les nombreux ouvrages en collaboration remarquons les ouvrages suivants : avec Luciana di Leone Ler Drummond hoje (Copetti Editores, 2014) ; avec Daniel Link et Italo Moriconi, Teoria, Poesia, Crítica, (Ed. 7 Letras, 2012) ; avec Carlos Capela, le volume de la revue outra travessia consacré à l'œuvre de Giorgio Agamben y Georges Bataille, “A exceção e o excesso: Agamben \& Bataille", $n^{\circ}$ 6, 2006. Elle a par ailleurs édité, avec Marcos Siscar et Alberto Pucheu, O duplo estado da poesía (Ed. Iluminuras, 2015), Alteridades da poesia contemporânea (Ed. Iluminuras, 2016), Linhas de fuga: modernidade e contemporaneidade na poesia (Ed. Iluminuras, 2016). sscramim@uol.com.br 